$-1$

\title{
Strategic Aspect of Knowledge Management
}

\author{
Olja Arsenijević', Dragan Trivan', Iztok Podbregar², Polona Šprajc² \\ 1 University "UNION-Nikola Tesla", Faculty of Business Studies and Law, Staro Sajmiste 29, 11070 Belgrade, Serbia \\ olja.arsenijevic@fpsp.edu.rs, dtrivan@gmail.com \\ ${ }^{2}$ University of Maribor, Faculty of Organizational Sciences, Kidriceva cesta 55a, 4000 Kranj, Slovenia \\ iztok.podberegar@fov.uni-mb.si, polona.sprajc@fov.uni-mb.si
}

\begin{abstract}
Background and Purpose: This paper analyses the strategic aspects of knowledge management in organizations in Serbia, from the theoretical and empirical point of view. In its theoretical part, the paper analyzes the latest literature in the fields of knowledge management, relations between communications strategyes and knowledge management, generations of knowledge management and organizational culture.

Design/Methodology/Approach: In its empirical part, the paper deals with determining the level of knowledge management in Serbian organizations through diffrent generations of knowledge management, as well as the problem with explicit and tacit knowledge management. The hypotheses were tested using data colleted from organizatons in Serbia via questionnaire, which consisted of 50 questions to examine five key factors in knowledge management. Results: The results showed that out of 41 indicators, only eight are rated positively. Results of t-test indicate significant distinctions within factors affecting the quality of knowledge management, as well as differences in quality of explicit and tacit knowledge management, therefore they confirmed both hypotheses.

Conclusion: The knowledge management projects in organizations in Serbia are initiated, as well as that belonging to the first generation of knowledge management can be defined.
\end{abstract}

Keywords: knowledge management; strategy; explicit knowledge; tacit knowledge; knowledge generations

\section{Introduction}

Organizations based on the work and the capital are increasingly being replaced by the organizations based on the knowledge, because their success and survival is conditioned by the creation of new, better and innovative products and services. As a result of globalization, companies are involved in a complex unprecedented volume of information, generating, in turn, a need to create products for current markets and dealing with new competitors, which requires their constant innovation (Garcia, \& Coltre, 2017). The work based on knowledge is not any more the feature of only new information technology companies, but it is the feature of almost all organizations, in all fields. Knowledge has become a main source of wealth, and knowledge workers are the most vital asset, and how to manage knowledge is the most important task for all organisations and individuals (Wu, Ming, Wang, \& Wang,
2016). It requires multidisciplinary expert knowledge and common learning in order to achieve the complex synthesis of contemporary technologies and specific domains of knowledge. The characteristic of organizations based on knowledge is the strategic and technical expert knowledge that provides them competitive position towards. Company's knowledge management is a framework that considers business processes as the processes which create value added knowledge and empower knowledge management processes through changing and correcting processes, systems, and organizational culture with the help of knowledge tools and techniques (Shannak, Ra'ed, \& Akour, 2012).

According to some authors (Ghisi, 2014) we are now in the knowledge era which requires a certain knowledge economy. Knowledge-based companies originate profits from the commercialisation of the knowledge created by their employees (Royal, Evans, \& Windsor, 2014). Name- 
ly, a great part of the investments of an organization goes to the growth of knowledge and competences, i.e. to the increase of human capital. The stock of competencies, knowledge, social and personality attributes, including creativity, embodied in the ability to perform work to produce economic value, is generally termed as human capital (Royal, Evans, \& Windsor, 2014). Another part of investments goes to the development of information technologies, which can lead for a while in a drop of profits, but with a simultaneous increase of the value of organization (see for example Mitra, Sambamurthy, \& Westerman, 2011, 57).

The change of the role of human capital (i.e. knowledge, skills and experience of employees) capital requires a new type of leader, able to keep up with the rapid changes in an organization. It is important for managers in organizations to actively leverage subordinates' human capital and to specifically focus their attention on the processes of converting their tacit knowledge to explicit knowledge. This becomes a critical activity in the performance management domain (Lakshman, 2014). A leader who will stimulate the transformation of individual knowledge into explicit organizational knowledge and connect the human, structural and client's capital in order to define a better business strategy will acquire an advantage in relation to the competition.

\section{Theoretical background}

As a ticket for the future, the organizations have begun to use knowledge more and more. The main characteristic of a modern social and economic life in its every aspect are changes (Kastratovic, Arsenijevic, \& Miletic, 2016). "Why do firms differ?" A number of researchers in the field of strategy has raised this question. An answer to this question also sets the knowledge-based view of strategy (KBS) apart from other schools of thought of strategy: firms differ not just because they have different value chains and activity systems or different resources and competencies, but because they envision different futures (Takeuchi, 2013). Many authors believe that the success of a particular business strategy, among other things, depends on a coordinated resource management, which implies a coordination of the two main forms of resources that the organizations are using: (1) physical resources - money, equipment, material, buildings and time and (2) conceptual resources - data, information and knowledge (Carneiro, 2000). Therefore, we can say that for them the success of the company requires the coordination of physical, i.e. material or tangible, conceptual, i.e. intangible, resources, while a good and coordinated management provides both resources for the company to acquire and maintain competitive advantage. However, the other authors advocate for a narrower view of the resources that enable success to the company. Thus, Sharp (2006) believes that success of an organization is directly related to the manner in which we can create, use and measure intangible resources, by which a circle of crucial resources is narrowed, i.e. it directly points to the fact that today physical resources are no longer crucial for the success of the company. Similar opinion also has Kermally (2002) who says, that the intangible property plays a major role in a construction of the abilities of the company and defines that an intangible property consists of the people and their knowledge, buyers, culture, brand, process and own technology and innovations. In accordance to that, in order to rexamine the claims mentioned, Sánchez, Chaminade and Olea (2000) use Barney test. A test consists of characteristics that a particular resource must meet in order to possess the potential that provides a sustainable competitive advantage to the company. Those characterisics are: it must have its value that is visible through the ability of the resource to use the advantage or neutralize the threats from the environment; it must be rare among the current and future competitors of the company; it must be impossible to imitate; there does not exist a substitute that has the same value and it has to be rare (Barney, 1991). They stress that the intangible resources are the only ones that pass Barney test, because in essence the majority of traditional sources of competitive advantage have become easily accessible. Nowadays, the most important role in the creation of a competitive advantage has the knowledge. Knowledge sharing practices among individuals, groups and units are essential for organizations, to create, share, capture and application of knowledge that enables organizations to improve resource structuring and capacity building (Rehman, Ilyas, \& Asghar, 2015). The growing importance of knowledge sharing practices has encouraged the managers to emphasize more on KMS because it helps to align the organization processes, structure and culture for better sharing of knowledge which may lead to better performance outcomes (Rehman, Ilyas, \& Asghar, 2015). Improving competitiveness should take the inter-relationships and dependencies arising from the implementation of innovative processes, creating organizational aspects of management in the processes of modernization and revitalization of enterprises into account (Firlej, 2012).

In the literature, the appropriate management strategy that deals with knowledge in organizations is labelled with the term knowledge management. Knowledge, like all other resources has to be properly managed. Otherwise it will be lost, become useless or even counterproductive creating a chaos. Knowledge management is a set procedures developed to prevent such loss to take place (Hajdić, \& Dulčić, 2013). Knowledge management is the explicit and systematic management of vital knowledge and its associated processes of creating, gathering, organizing, diffusion, use and exploring. It requires turning personal knowledge into corporate knowledge that can be widely shared throughout an organization and appropriately applied (Anand, \& Singh, 2011). In an organization, knowl- 
edge management represents the sharing of knowledge through an ongoing process of development and constant improvement, which increases the innovative capabilities of employees (Batra, 2010). In its simplest form, knowledge management involves three activities: knowledge acquisition, knowledge dissemination, and receptiveness to knowledge within the organization (Ooi, Teh, \& Chong, 2009).

The information and knowledge are the thermonuclear competitive weapons of our time. Knowledge management is presently of specific interest to economists dealing with corporate governance, as over the last four decades they have noted a lack of influence of the traditional factors of competitive advantage due to the growing impact of global processes, diffusion of innovation and the widespread uptake of modern technologies in production processes (Firlej, \& Žmija, 2017). A knowledge is more valuable and more powerful than the natural resources, big factories, or fat bankrolls. Knowledge is designed to contribute to the development of the society, improve the competitiveness of the economy, and should also help to achieve better results for companies and an increase in their value (Firlej, \& Žmija, 2017). The knowledge management is a system that integrates people, processes and technology for sustainable results, by increasing performance through learning (Gorelick, \& Tantawy-Monsou, 2005).

For knowledge management, we can say that it is the „recognition, creation, documentation, distribution and transfer of tacit and explicit knowledge among the individuals for the purpose of increasing organizational success" (Jackson, DeNisi, \& Hitt, 2003). Or that it is ,,a framework that implies setting of the system, process and culture in order to manage one of the more important corporative resources - knowledge". By explicit knowledge, we refer to the knowledge that we exteriorise and formulate (Collins, 2010). Studies draw on explicit knowledge, citing rewards (Shalley, Zhou, \& Oldham 2004) opportunities to learn new skills and knowledge (Amabile, Conti, Coon, Lazenby, \& Herron, 1996) varied work paths, exposure to new perspectives (Williamson, 2006) and team working (West, \& Farr 1990) as key drivers for enhancing creativity. Explicit knowledge refers to the knowledge which can be articulated, codified, communicated and stored in formal language or with the use of symbols such as grammatical statements, mathematical expressions, specifications, technical manuals, written procedures etc. (Nonaka, \& Takeuchi, 1995). Tacit knowledge is knowledge within the individual. It originates from action, experience and involvement in a specific context. The tacit dimension of knowledge is comprised of cognitive elements (an individual's mental models consisting of mental maps, beliefs, paradigms and view-points) as well as technical component (crafts, skills, and know-how that apply to a specific context) (Alavi, \& Eeidner, 2001). Tacit knowledge is characterized by the difficulty of being trustworthily formalized though a language that can be registered and shared, as in general, it is stored in the individuals' mental structures and it is displayed through the beliefs, experiences and working practices (Paolino, Paggi, Alonso, \& Lopez, 2014). Call warns that a vague definition of knowledge management probably simultaneously represents the cause for the success of this field, as well as the threat for its failure. The main goal of the systemic knowledge management is to provide a tacit and explicit knowledge and creation of the conditions for innvations for the purpose of the better quality of a decision-making process. More precisely, the goal of a knowledge management should be the correlation of the questions with answers or the people who know the answer. The goal is to enhance organizational performance by explicitly designing and implementing tools, processes, systems, structures, and cultures to improve the identification, capture, validation, and transfer knowledge critical for decision making (Leavitt, \& O’Dell, 2004). A knowledge may grow from subliminal to idealistic as it becomes better established and understood, then to systematic, then to pragmatic, and finally to the automatic knowledge when it is very well understood. From the well established knowledge we can then start to glimpse new ideas and concepts through creativity and innovation (Wiig, 1991).

Relations between a knowledge and strategy in the organization can be observed from the standpoint how much the knowledge and the efficient knowledge management contribute to the competitive advantage of particular organization. Some definitions of the knowledge management relate it even directly to the desired or achieved competitive advantage.

The strategy represents a certain knowledge by itself. It consists of certain knowledge structures which can be articulated and can be followed throughout their changes in time and classified into crucial and supporting elements. This knowledge is most frequently possessed by the top management of the company, but it can also be more widely distributed. It consists of the knowledge of mission and goals, knowledge of the competition, knowledge of clients (buyers), knowledge of the industry and relations between these domains of knowledge.

\subsection{Relationship between knowledge management and organizational cul- ture}

By the organizational culture, we usually imply the system of assumptions, beliefs, values and norms of behavior that the majority of the members of one community have developed and adopted through the joint work and experience and which direct their way of thinking and behaviour.

One of the globally most accepted commercial tools for the evaluation of organizational culture is OCI (Or- 
ganizational Culture Inventory). The OCI can be used to obtain reliable data on the behavioral norms of the organization and/or its sub-units, validate a need for cultural change on the part of participants, identify the areas where change needs to take place, develop a vision for culture change, create individual and organizational action plans for effecting cultural change, evaluate the impact of organizational change efforts (Cooke, \& Lafferty, 2012). With this instrument, we measure 12 different, but related sets of norms of behavior and expectations, which are implicitly or explicitly required from the employees in order to meet the expectations of the organization or particular business unit. These twelve sets of behavior norms are categorized into three basic clusters or types of organizational culture: constructive, passive defense and aggressive defense. By focusing on behavior norms, instead of global aspects of the culture, such as common values and beliefs (although they are closely related), OCI is more aimed towards everyday activities of organization's members and thus the entire concept of organizational culture seems less abstract and easier for understanding and management.

\subsection{Generations of knowledge manage- ment}

As the field of the knowledge management is rather young and has started to develop at the time when the changes in business world has appeared rapidly and constantly, thus the characteristics of the knowledge management concept are rapidly changing and adapting to the business environment. Today, these changes in the field of knowledge management are referred to as the generations, i.e. phases of knowledge management. There are three generations of knowledge management mentioned in the literature that relatively rapidly replaced one another. Thus, McElroy (2000) writes that he has spotted a change in practice of knowledge management (i.e. transfer from the first to the second generation) and only a few years later, in the literature appears the third phase of development cycle of the knowledge management (Koenig, \& Srikantaiah, 2004). However, this kind of a rapid development cannot be simultaneously finded in practice, and thus Carrillo (2006) writes that the first and second generation of knowledge management are rather widespread, while the third phase is in its beginnings.

The first generation of knowledge management starts with observing the company and its abilities through the resources that it owns, i.e. the acceptance of resource theory of the company's strategy, which has led to the knowledge management development. First-generation of knowledge management seeks only to enhance the integration of existing organizational knowledge through strategies such as knowledge capture and sharing (Kmci.org, 2017).

The second generation of knowledge management has resulted from the need for solving one of the main problems from the first generation - the inadequate organizational culture, which does not support the activities of knowledge management and focuses on the human and culturological dimension. Second-generation of knowledge management strives to improve knowledge integration, too, but it also seeks to improve knowledge production (Kmci.org, 2017). The top management in this generation becomes an important actor, which along with the development of awareness of the role of knowledge in a modern business world invests more and more in good management. The second generation of knowledge management revolves around the transfer of knowledge and the best practice (Sherif, 2006). This generation is also characterized by the interest for the measurement of specific benefits from the implementation of knowledge management activities.

The third generation of knowledge management is focused on simplification of the process of coding the knowledge and information, as well for its preservation so the knowledge is always and at any moment easily accessible. The characteristics of a third generation of knowledge management are: the company optimally takes care of all the factors that affect the successful knowledge management, a special care is paid to coding and storage of information and knowledge for the sake of simplicity in the access and using of them. The practical implications of the third generation of knowledge management are far-reaching and profound. Out of the third generation knowledge management school of knowledge management theory and practice has come a new type of organization in which knowledge is continually being developed and is always open to criticism: The Open Enterprise. Creating and maintaining such environments, even as command and control styles of management continue to prevail, is the overriding vision of the third generation of knowledge management. The result? High-performance knowledge processing, sustainable innovation, and greater levels of corporate integrity and accountability (Kmci.org, 2017).

Problem of the research was to establish whether there is knowledge management in Serbian organizations and at which level it is. We set our goal as to determine the level of knowledge management in Serbian organizations through diffrent generations of knowledge management, as well as the problem with explicit and tacit knowledge management.

\section{Method}

The goal of our research is to test the following two research hypothesis $(\mathrm{RH})$ :

\section{Hypotheses}

The initial hypotheses that were the starting point of the research are: 


\section{H1: Organizations in Serbia are in the first phase of knowl-} edge management.

In the literature, the definition in the first phase of knowledge management was the introduction to describe the management activity concerned with implementing such solutions, in order to gain competitive advantage and to increase productivity and effectiveness (Firestone, McElroy, 2003). Based on the different generations of knowledge management, we've analysed the organizations in Serbia as from the standing point of the development.

\section{H2: In organizations in Serbia it is managed more with explicit than tacit knowledge.}

The categorization of knowledge into tacit or explicit has become a cornerstone in the literature on learning and knowledge management (Becerra, Lunnan, \& Huemer, 2008). Our hypothese is pushing our understanding of how these two sorts of knowledge flows between organizations in Serbia.

\section{Methodology}

An instrument that was used in the study consisted of the questionnaire for the measurement of crucial factors in knowledge management (the questions are grouped into five units for examining the five key factors in knowledge management and it contains 50 questions, the key factors are: infrastructure, carriers, organizational culture, IT and usefulness measurement) (Vidović, 2008). When designing the questionnaire we've adapted the questionnaire from the master thesis (Vidović, 2008).

For data processing, we have used the statistical software SPSS. In addition to descriptive statistics, the difference between arithmetic means was also tested by T-test, as well as variance analysis ANOVA.

\section{The sample of respondents}

Studies have included Serbian companies chosen from APR (The Serbian Business Register Agency) register. The sample consisted of medium and big companies and there was a total of a 100 of them. The characteristics of the companies examined: by the size - from 50 to 250 of employees $29,5 \%$, from 250 to 500 employees $35,3 \%$, from 500 to 1000 employees $17,6 \%$, more than $1000 \mathrm{em}$ ployees $17,6 \%$, from different industrial branches with private $(50 \%)$ and state $(50 \%)$ ownership structure.

\section{Results}

By the conducted research, 41 indicators of the general state of knowledge management in Serbia has been collected. The collected indicators were grouped according to key factors that influence the knowledge management. In order to better implement the analysis of knowledge management practices in Serbian companies, ratings of the level indicator are listed (+ or -), depending on whether the indicator indicates a positive or a negative practice of knowledge management. He positively assessed indicator of knowledge management practices if it is recorded in $50 \%$ and more companies, a negative estimated is one that is present in less than $50 \%$ of them.

The questions from the questionnaire are presented in the appendix. By the analysis of answers to 11 asked questions that refer to the infrastructure of knowledge management (see Appendix; questions no. 1 to 11) we can conclude that only two indicators point to the positive practice of knowledge management in Serbian companies: $69 \%$ of organizations have a list of crucial knowledge and $55 \%$ of them plan and implement the knowledge of the employees according to the real needs of the company. The other indicators (comparison of the required and available knowledge at the annual level $38,5 \%$, education of more than $50 \%$ of employees in the previous year - $36,3 \%$, low fluctuation of employees after the education $34 \%$, employment of more than $50 \%$ of new workers due to specific knowledge and skills that the organization needs $36 \%$, more than $1 \%$ of employees perform the jobs of knowledge management $10,5 \%$, the existence of own library with books and journals from the fields relevant for the company $45,1 \%$, the existence of the obligation to transfer the interesting things and the knowledge acquired from the conferences $-22,6 \%$, congresses and etc to other colleagues, implementation of the practice of meetings after the completion of projects with the aim to determine the acquired knowledge and experiences on the project $-20,9$ $\%$, an insight into the experiences acquired and practice available to the employees who have not participated in those projects- $25,5 \%$ ) that refer to education of employees and the transfer of tacit and explicit knowledge in an organization cannot be positively evaluated because they are not carried out in more than $50 \%$ of organizations.

When we talk about the indicators that refer to knowledge carriers (see Appendix; questions from no. 12 to 21) as a key indicator in success of knowledge management, it is important to mention that it is possible only to observe the state of facts and not determine whether it is positive or negative from the perspective of the knowledge management practice and it refers to the indicators on a person responsible for the knowledge management. From the ten indicators (knowledge is mentioned in the mission - 15,5 $\%$, there is a person at the level of organization responsible for knowledge management $-45,2 \%$, person for knowl- 
edge management is in top management - 23,6 \%, person for knowledge management is in the human resources management sector- $86,2 \%$, person for knowledge management takes care of the education and development of employees - $50 \%$, observing operating success of the employees with a contribution to knowledge management $-29 \%$, observation of contribution to knowledge management in case of more than $50 \%$ of employees $-10 \%$, rewarding the contribution of employees to knowledge management $58 \%$, there is an official program of mentoring for the newly-employed $-48,4 \%$, more than $5 \%$ of employees take part in the mentorship program $-26,7 \%$ ) only two can be evaluated as positive practice of knowledge management and they refer to rewarding of the employees and the existence of official mentoring program for the newly-employed. From the results, we can also observe the fact that top management does not provide a sufficient support to knowledge management. This can be concluded from the fact that a small percentage of the company has the knowledge management positioned at a strategic level, only $28.6 \%$, or the importance of the knowledge involved in the organizational mission statement - 18.5\%. Lack of support from top management, according to its frequency, is the third most common barrier that occurs as an obstacle to the introduction or maintenance of a system of knowledge management in Serbian enterprises. On the first and second place, there are barriers relating to the lack of available time of employees and lack of initiative to launch the knowledge management.

Study of the indicators that refer to organizational culture (see Appendix question no. 22 ) has led to the conclusion that only one of the nine indicators can be evaluated as positive for the practice of knowledge management and that is the existence of a room predicted for informal socializing of employees during the working hours: according to the perception of the person in charge of $\mathrm{KM}$, open communication mainly prevails $-6,4 \%$, according to the perception of a person in charge of $\mathrm{KM}$, there prevails the confidence among the employees $-23,7 \%$, according to the perception of a person in charge of $\mathrm{KM}$, employees mainly mutually share their knowledge $-34 \%$, according to the perception of a person in charge of KM, the employees mainly openly talk about the level of their knowledge
$-15 \%$, according to the perception of a person in charge of $\mathrm{KM}$, the company is innovative $-35 \%$, according to the perception of a person in charge of KM, the employees have time to talk to their colleagues $-38,6 \%$, according to the perception of a person in charge of $\mathrm{KM}$, there is a room for socializing of the employees during the working hours $-51,2 \%$. We can conclude that all the indicators point to the lack of knowledge culture, which implicitly points out to a very bad condition when it comes to knowledge management.

From the indicators that refer to IT (see Appendix; questions from no. 23 to 32 ), three can be evaluated positively, more precisely: the company uses IT for managing the documents for the purpose of knowledge transfer $-58,3 \%$, the company for more than $50 \%$ of its employees provides the connection through IT $-65,3 \%$, company in yellow pages mentions the data for more than $50 \%$ of its employees $-57 \%$. The other six indicators have a negative foresign: the company uses a software for knowledge management $-21,5 \%$, the company uses IT in order to support dynamic communication in the form of questions and answers, online survey and offers the information on novelties within the company $-42,3 \%$, the company publishes new documents or texts on daily basis through IT for documents management - 31\%, the company uses IT for the needs of creating knowledge basis and it provides a simple archiving, categorization and browsing of specific, expert knowledge $-35,6 \%$, they use IT for yellow pages $-31,3 \%$, companies that believe that yellow pages should contain the data for more than $50 \%$ of employees $-45 \%$.

The last segment of the indicators refers to those who point to the measurement of the benefits of knowledge management (see Appendix; questions no. 33 and 34). Those are: the companies that have indicators regarding knowledge management $-12,3 \%$ and companies that record and transfer their experiences that confirm the importance and usefulness of knowledge management - $42 \%$. As it can be seen from the answer, both indicators can be evaluated negatively.

When we observe the indicators for all five factors in summary, we can conclude that the poorest indicators are related to measurement of the usefulness of knowledge management, then carriers of knowledge management,

Table 1: Percentage of the positive indicators of the practice of KM in organizations in Serbia

\begin{tabular}{|c|c|c|c|}
\hline Factor that indicators refer to & Number of indicators & Percentage of indicators favourable for KM & Rank \\
\hline Infrastructure & 11 & $18,2 \%$ & 3 \\
\hline Carriers & 10 & $25 \%$ & 2 \\
\hline Organizational culture & 9 & $11,1 \%$ & 4 \\
\hline IT & 9 & $33,3 \%$ & 1 \\
\hline Usefulness measurement & 2 & $0 \%$ & 5 \\
\hline Total & $\mathbf{4 1}$ & $\mathbf{1 9 , 5 \%}$ & - \\
\hline
\end{tabular}


and organizational culture. The best are those indicators that are related to IT which are used for knowledge management. Of the total of 41 indicators, only eight are positively evaluated, which points to a relatively bad practice of knowledge management in medium and big companies in Serbia, which is shown in Table 1.

When we talk about the grades of key factors, it is important to notice that IT factor has got the highest average grade $-3,31$, and measurement of usefulness the lowest 2,22 . The results tell us that IT as a support to knowledge management is the most developed in all the organizations examined and the measurement of usefulness is still at its beginning.

In Table 2. the frequency of evaluation of the key factors that influence the knowledge management in Serbian enterprises is given. Assessment of key factors, as shown in Table 2, which shows the arithmetic means, standard deviations, and the range of rating the quality of the key factors of knowledge management in Serbian companies, move in the same direction as the indicators of the factors discussed in the previous part of this study because they they are based on them. Their frequencies are, however, mentioned in the purpose of more detailed analysis of the state of knowledge management in Serbian enterprises

\section{Analysis}

In this section we will present statistics of our research and attempt to determine the answers to our research hypothesis.

H1 Organizations in Serbia belong to the first genera- tion of knowledge management

In order for the hypothesis set to be accepted or rejected, we have started the analysis of the existence of statistically significant difference among the grades that were attributed to organizations for the IT quality management, as basic factor of the first generation of knowledge and grades that are assigned to other factors, by applying t-test for dependent variables.

Having in mind the percentage of favourable indicators and average grade given in Tables 1 and 2, we have established that the organizations in Serbia are focused on IT significantly more than to other factors.

Looking at the percentage of favorable indicators and the average marks awarded, Serbian companies focus more on information technology than on other factors that influence the quality and success of knowledge management (Tables 3 and 4). From a total of 41 indicators, only 8 is rated positively for the practice of knowledge management, which indicates a relatively poor practice in terms of overall knowledge management practice in Serbia.

The data presented in Table 4 show that information technology is the most estimated, suggesting that it is best developed in the Serbian companies and to support knowledge management, while the least developed is measuring the usefulness of knowledge management.

However, in order to determine whether they are statistically significant differences between the arithmetic means of evaluation factors, it was necessary to carry out the t-test, whose results are given in Table 5.

The results of the t-test point to statistically significant differences of the two pairs of factors: IT and carriers -

Table 2: Frequency of the grades for key factors that affect knowledge management

\begin{tabular}{|c|c|c|c|}
\hline Factor that indicators refer to & Arithmetic mean & Standard deviation & Rank \\
\hline Infrastructure & 3,26 & 1,24 & 2 \\
\hline Carriers & 2,56 & 0,99 & 4 \\
\hline Organizational culture & 3,09 & 0,89 & 3 \\
\hline IT & 3,31 & 1,47 & 1 \\
\hline Usefulness measurement & 2,22 & 1,43 & 5 \\
\hline
\end{tabular}

Table 3: Percentage of favorable indicators of KM practices in Serbian companies, according to groups of indicators

\begin{tabular}{|c|c|c|c|}
\hline Factor relating to the set of indicators & $\begin{array}{c}\text { Number of } \\
\text { indicators }\end{array}$ & $\begin{array}{c}\% \text { of indicators favorable } \\
\text { to the practice of KM }\end{array}$ & Ranking \\
\hline Infrastructure & 11 & $18,2(2 / 11$ & 3 \\
\hline Carriers & 10 & $25(2 / 8)$ & 2 \\
\hline Organizational culture & 9 & $11,1(1 / 9)$ & 1 \\
\hline Information technology & 9 & $33,3(3 / 9)$ & 5 \\
\hline Usefulness measurement & 2 & $0(0 / 2)$ & - \\
\hline Total & 41 & $19,5(8 / 41)$ & 4 \\
\hline
\end{tabular}


Table 4. Arithmetic means, standard deviations, and the rank score of the quality of the key factors in KM in Serbian enterprises

\begin{tabular}{|c|c|c|c|c|}
\hline Factor relating to the set of indicators & $\mathrm{n}$ & $\begin{array}{c}\text { Arithmetic } \\
\text { means }\end{array}$ & $\begin{array}{c}\text { Standard } \\
\text { deviation }\end{array}$ & Ranking \\
\hline Infrastructure & 34 & 3,26 & 1,24 & 2 \\
\hline Carriers & 34 & 2,56 & 0,99 & 4 \\
\hline Organizational culture & 32 & 3,09 & 0,89 & 3 \\
\hline Information technology & 32 & 3,31 & 1,47 & 1 \\
\hline Usefulness measurement & 32 & 2,22 & 1,43 & 5 \\
\hline
\end{tabular}

Table 5: Results of the t-test for dependent variables that are used to examine the difference between factors that affect the quality of KM in organizations in Serbia.

\begin{tabular}{|c|c|c|}
\hline & t-value & Significance \\
\hline Pair 1: IT - Infrastructure & $-0,133$ & 0,895 \\
\hline Pair 2: IT - Carriers & $-2,438$ & $\mathbf{0 , 0 2 1}$ \\
\hline Pair 3: IT - Organizational culture & $-0,793$ & 0,434 \\
\hline Pair 4: IT - usefulness measurement & 3,029 & $\mathbf{0 , 0 0 5}$ \\
\hline
\end{tabular}

significance level 5\% and IT and knowledge management usefulness measurement - significance level $1 \%$. For the other two pairs, there were not established statistically significant differences. From these findings, it is obvious that in the organizations examined there lacks the support of top management for the knowledge management projects, which is also the problem in organizations that are in the first generation of knowledge management. And as usefulness management comes as the last phase in knowledge management, it is quite clear that organizations in Serbia are still in the first generation.

When it comes to the relationship between the assessment of information technology and infrastructure, the result indicates a lack of statistically significant differences. This is logical. In practice, usually with the launch of the system for knowledge management, the infrastructure that supports is also developing, and that is why there are no differences here. Also, the difference between the average ratings information technology and organizational culture did not show statistically significant. The assumption is that the company started its activities with knowledge management, with the construction of information technology and adequate adaptation of business processes, but have not yet reached the level when the carriers systematically advocate and support knowledge management.

Having in mind all the factors mentioned, we can conclude that the first hypothesis is confirmed according to which the organizations is Serbia are in the first generation of knowledge management.

H2 says that organizations in Serbia more manage the explicit than implicit knowledge.
In order to accept or reject the hypothesis set, we have accessed the t-test for dependent variables: management of the explicit knowledge and management of the tacit knowledge. The results are shown in Table 6.

The evaluations presented in the Table point to the conclusion that organizations in Serbia are more successful in explicit knowledge management. Data that refer to the mean value point to the fact that the difference is statistically significant at the level 0,05 . This means that with $95 \%$ of certainty we can claim that organizations examined are better in managing the explicit than tacit knowledge.

Based on the results obtained, we can also confirm the $\mathbf{H} 2$ which says that organizations in Serbia more manage the explicit than tacit knowledge.

Based on the analysis of the score frequency of the key factors that influence the knowledge management in Serbian enterprises, can be concluded that there are differences in the quality factors of knowledge management. As the total score of knowledge management is based on the marks awarded for all five factors, namely, includes the quality of the key factors, it can be said that the total score of knowledge management is the one which gives picture of the situation of the system of knowledge management in a company.

\section{Conclusion}

As many other European transitional countries, Serbia lost a significant amount of employment, especially during the privatization phase that was initiated by the adoption of the new privatization regulation in 2001. Beside the decline in the employment, the effects of the privatization have been 
Table 6: Results of the t-test for dependent variables that were used to examine the difference between evaluation of the quality of explicit, i.e. tacit knowledge management in organizations in Serbia.

\begin{tabular}{|c|c|c|cc|}
\hline & Mean value & Standard deviation & t & Sig. \\
\hline $\begin{array}{c}\text { Explicit knowledge } \\
\text { management level }\end{array}$ & 3,42 & 1,57 & $-2,56$ & 0,016 \\
\hline $\begin{array}{c}\text { Tacit knowledge management } \\
\text { level }\end{array}$ & 2,80 & 1,17 & \\
\hline
\end{tabular}

also manifested through changes in the structure of the corporate sector in Serbia (Ognjenović, 2015).

Based on the research carried out and the analysis of the obtained results, we can conclude that both hypotheses set are confirmed.

Although the results are not at the highest level when it comes to knowledge management in organizations in Serbia, we can conclude that the knowledge management projects are initiated, as well as that belonging to the first generation of knowledge management can be clearly defined. Each component of the knowledge management construct will positively affect innovation. In order for innovation to occur, managers first need to have knowledge about the internal and external forces that affect the firm - the more knowledge, and the greater the variety of knowledge, the better. Second, knowledge must flow freely around the firm - the better the dissemination of knowledge the greater the likelihood of innovation as more people within levels and departments of the organization are exposed to new knowledge that interacts with the knowledge already held. Lastly, an innovative organization is, by definition, responsive. In fact, innovation is a response in itself. Therefore, the more responsive and agile an organization is the more likely it is to be innovative (Darroch, 2005).

The analysis performed for the purpose of accepting or rejecting the second hypotheses, led to the conclusion that Serbian companies on average are most concerned with the management of explicit knowledge, that is easily visible and relatively easy to manage. As noted above, explicit knowledge represents only the tip of the iceberg, but tacit knowledge is that which is actually the most valuable for the company and one that really provides a competitive advantage. The management of explicit knowledge makes the first and indispensable step in the process of knowledge management, but it is important to emphasize that it can not stand at this level. Managing tacit knowledge is required and fluid process in which the biggest task lies on the real owners of that knowledge - to individuals. Creating a culture that encourages sharing tacit form of knowledge is the key to success and survival of the company.

Knowledge is becoming one of the most important resources of the company, regular "guidance" of employees in terms of training, education and development of crucial skills become imperative in business (Arsenijević, Lilić, \& Zdravković, 2015). Information and knowledge form a virtous circle. Knowledge can't exist without information. With good information, people can make better decisions and take intelligent action (Henderson, 2000).

Organizations in Serbia should work on when ir comes to knowledge management is the measurement of usefulness and support of the top management.

The research carried out has its constraints that are reflected in the number of organizations included by the research, but still it included medium and big companies.

However, based on the implemented research for the organizations in Serbia when it comes to knowledge management: it is required to work much more on the implementation of the activities of knowledge management projects, focus on the management of tacit knowledge, greater support of top management, create and develop organizational culture that will largely support the the knowledge management and aim it towards the culture of the learning organization.

\section{References}

Alavi, M., \& Leidner, D.E. (2001). Review: Knowledge Management and Knowledge Management Systems: Conceptual Foundations and Research Issues. MIS Quarterly, 25(1), 107-136, http://dx.doi. org $/ 10.2307 / 3250961$

Amabile, T. M., Conti, R., Coon, H., Lazenby, J., \& Herron, M. (1996). Assessing the work environment for creativity. Academy of Management Journal, 39(5), 1154-1184, http://dx.doi.org/10.2307/256995

Anand, A., \& Singh, M.D. (2011). Understanding Knowledge Management: a literature review. International Journal of Engineering Science and Technology, 3(2), 926-939.

Barney, J. (1991). Firm resources and sustained competitive advantage. Journal of Management, 17(1), 99120, http://dx.doi.org/10.1177/014920639101700108

Batra, J. (2010). Knowledge management: Emerging practices in IT industry in NCR. The IUP Journal of Knowledge Management, 8(1\&2), 57-67.

Becerra, M., Lunnan, R., \& Huemer, L. (2008). Trustworthiness, Risk, and the Transfer of Tacit and Explicit Knowledge Between Alliance Partners. Journal of Management Studies, 45(4), 691-713, http://dx.doi. 


\section{org/10.1111/j.1467-6486.2008.00766.x}

Carneiro, A. (2000). How does knowledge management influence innovation and competitiveness? Journal of Knowledge Management, 4(2), 87-99, http://dx.doi. org/10.1108/13673270010372242

Carrillo, F. J. (2006). From transitional to radical knowledge-based development. Journal of Knowledge Management, 10(5), 3-5, http://dx.doi. org/10.1108/13673270610691125

Collins, H. (2010). Tacit and explicit knowledge. Chicago and London: The University of Chicago Press.

Cooke, R.A., \& Lafferty, J.A. (2016). Organizational Culture Inventory. Retrieved from http://www.humansynergistics.com/docs/default-source/product-info-sheets/ oci-product-info-sheet.pdf?sfvrsn $=18$

Darroch, J. (2005). Knowledge management, innovation and firm performance. Journal of Knowledge Management, 9(3), 101-115, http://dx.doi.org/10.1108/13673270510602809

Firlej, K. (2012). Knowledge Management and Diffusion of Innovations In the Process of Restructuring Agriculture and Food Industry Companies. In Knowledge Management and Diffusion of Innovations In the Process of Restructuring Agriculture and Food Industry Companies (pp. 83-93). Ostrołęka: Wydawnictwo Wyższej Szkoły EkonomicznoSpołecznej w Ostrołęce.

Firlej, K., \& Žmija, D. (2017). The specificity of knowledge management in the food industry in Poland. Business Administration and Management, 10(1), 83-97, http://dx.doi.org/10.15240/tul/001/2017-1-006

Firestone, J.M., \& McElroy, M.W. (2002). Generations of Knowledge management. Executive Information Systems, 1-51, http://dx.doi.org/10.1016/B978-0-75067655-7.50008-0

Garcia, O.P.G., \& Coltre, S.M. (2017). Knowledge management as a determing factor in the retention of professionals in the industry: A case study in an organization in the furniture industry. Brazilian Business Review, 14(2), 182-203, http://dx.doi.org/10.15728/ bbr.2017.14.2.3

Ghisi, M.L. (2014). Knowledge society: Entering a post capitalist era? Creative and knowledge society, 4(1), 1-26. Doi: https://doi.org/10.2478/cks-2014-0003

Gorelick,C.,\&Tantawy-Monsou,B.(2005).Forperformance through learning, knowledge management is the critical practice. The Learning Organization, 12(2), 125-139, http://dx.doi.org/10.1108/09696470510583511

Hajdić, M., \& Dulčić, F. (2013). Knowledge Management throughout Various Stages of a SME Life-Cycle. In Klepić, Z., Čizmić, E., Alfirević, N. (eds.). Zbornik radova (Posebno izdanje: Zbornik II. interkatedarskog skupa organizacije i menadžmenta), University of Mostar, Faculty of Economics, pp. 155-178.

Henderson, C. (2000). Successfully Implementing Knowledge Management. Texas: American Productivity and
Quality Center.

Jackson, S. E., DeNisi, A., \& Hitt, M. A. (2003). Managing knowledge for sustained competitive advantage: designing strategies for effective human resource management. San Francisco: John Wiley \& Sons.

Kastratovic, E., Arsenijevic, O., \& Miletic, L. (2016). Level of Tolerance to Changes in Vojvodina Enterprises. International Review, 1-2, 74-81, http://dx.doi. org/10.5937/intrev1602074K

Kermally, S. (2002). Effective knowledge management. West Sussex: John Wiley \& Sons.

KMCI.org. (2017). The new KM-what is it? Retrieved from http://www.kmci.org/the new knowledgement. $\underline{\mathrm{html}}$

Koenig, M.E.D., \& Srikantaiah, T.K. (2004). Three Stages of Knowledge Management. In Koenig, M.E.D., Srikantaiah, T.K. (eds.) Knowledge Management Lessons Learned: What Works and What Doesn't. ASIST, New Jersey, 3-8. Lessons Learned and Best Practices, pp. 19-30.

Lakshman, C. (2014). Leveraging human capital through performance management process: the role of leadership in the USA, France and India. The International Journal of Human Resource Management, 25(10), 1351-1372, http://dx.doi.org/10.1080/09585192.2013 .870310

Leavitt, P., \& O'Dell, C. (2004). The executive's role in knowledge management. Texas:.American Productivity \& Quality Center.

McElroy, M. W. (2000). Integrating complexity theory, knowledge management and organizational learning. Journal of Knowledge Management, 4(3), 195-203, http://dx.doi.org/10.1108/13673270010377652

Mitra, S., Sambamurthy, V., \& Westerman, G. (2011). Measuring IT performance and communicating value. MIS Quarterly Executive, 10(1), 47-59.

Nonaka, I., \& Takeuchi, H. (1995). The Knowledge-Creating Company: How Japanese Companies Create the Dynamics of Innovation. New York/Oxford: Oxford University Press.

Ognjenović, K. (2015). On-the-Job Training and Human Resoruce Management: How to Improve Competitive Advantage of an Organization? Organizacija, 48(1), 57-70, http://dx.doi.org/10.1515/orga-2015-0005

Ooi, K.B., Teh, P.L., \& Chong, A.Y.L. (2009). Developing an integrated model of TQM and HRM on KM activities. Management Research News, 32(5), 477-490, http://dx.doi.org/10.1108/01409170910952976

Paolino, L., Paggi, H., Alonso, F., \& Lopez, G. (2014). A model to capture and manage tacit knowledge using a multiagent system. AIP Conference Proceedings, 1618(1), 782-785, http://dx.doi.org/10.1063/1.4897848

Rehman, W.U., Ilyas, M., \& Asghar, N. (2015). Knowledge sharing, knowledge management strategy and performance. Pakistan Economic and Social Review, 
53(2), 177-202.

Royal, C., Evans, J., \& Windsor, S.S. (2014). The missing strategic link - human capital knowledge, and risk in the finance industry - two mini case studies. Venture capital, 16(3), 189-206, http://dx.doi.org/10.1080/136 91066.2014.916856

Salamazdeh, Y., Salamazdeh, A., \& Radovic Markovic, M. (2016). Cultural Intelligence and Network Organizations in Society: Case of The ran Neighborhood Councils. International Review. 1-2, 49, http://dx.doi. org/10.5937/intrev1602046S

Sánchez, P., Chaminade, C., \& Olea, M. (2000). Management of intangibles: An attempt to build a theory. Journal of Intellectual Capital. 1(4), 312-327, http:// dx.doi.org/10.1108/14691930010359225

Shalley C. E., Zhou J., \& Oldham G.R. (2004). The effects of personal and contextual characteristics on creativity: Where should we go from here? Journal of Management, 30, 933-958, http://dx.doi.org/10.1016/j. im.2004.06.007

Shannak, R.O., Ra'ed, M.M., \& Akour, M.A. (2012). Knowledge management strategy building: Literature review. European Scientific Journal, 8(15), 143-168.

Sharp, P. (2006). MaKE: a knowledge management method. Journal of Knowledge Management, 10(6), 100109, http://dx.doi.org/10.1108/13673270610709242

Sherif, K. (2006). An adaptive strategy for managing knowledge in organizations. Journal of Knowledge Management, 10(4), 72-80, http://dx.doi. org/10.1108/13673270610679372

Takeuchi, H. (2013). Knowledge-Based View of Strategy, Universiabusiness Review, Cuarto Triemestre. Universidad Complutense de Madrid, Spain.

Vidović, M. (2008). Upravljanje znanjem [Knowledge Management]. University of Zagreb, Faculty of Economics.

West, M.A., \& Farr, J.L. (1990). Innovation and Creativity at Work. Chichester: Wiley.

Wiig, K. (1999). Comprehensive Knowledge management. Texas: Knowledge Research Institute.

Williamson, B. (2006). Elephants Can’t Jump: Creativity, New Technology and Concept Exploration in Primary Science. In Warwick, E., Wilson, E., Winterbottom, M. (eds.) Teaching and Learning Primary Science with ICT. Maidenhead, Open University Press, pp. 70-93.

Wu, Z.Y., Ming, X.G., Wang, Y.L., \& Wang, L. (2014). Technology solutions for product lifecycle knowledge management: framework and a case study. International Journal of Production Research, 52(21), 6314-6334, http://dx.doi.org/10.1080/00207543.2014.935823
Olja Arsenijevic, $\mathrm{PhD}$, is full professor at the Faculty of Business Studies and Law in Belgrade "Union Nikola Tesla « University. Her major research interests concern management, education, marketing and safety issues. She has published several monographs, several research papers in domestic and international journals and presented her research work at many national and international conferences.

Dragan Trivan, $\mathrm{PhD}$ in Security and Protection Studies, associate professor at the Faculty of Business Studies and Law in Belgrade, "Union Nikola Tesla" University. Mr Trivan was elected to scientific titles in several countries. He is the president of Serbian Association of Managers in Corporative Security. $\mathrm{He}$ is also the author of several monographs and number of research papers presented at national and international conferences and published in domestic and foreign journals. For exceptional achievements in business, scientific, and humanitarian work, he was repeatedly awarded domestically and abroad. Professor Trivan is a member of the American Society of Criminologists and the International Association of Criminologists.

Iztok Podbregar (Ph.D) is a Full Professor at the Faculty of Organizational Sciences, University of Maribor and Dean. His major interests concern crisis management, critical infrastructure and human resource management. He teaches at undergraduate, master and doctoral level. He is author of several monographs, books, scientific articles published in Slovenia and abroad.

Polona Šprajc (Ph.D.) is an Assistant Professor at the Faculty of Organizational Sciences, University of Maribor in the Department of Personnel, and Vice dean for educational activity. Her major research interests concern human resource management, marketing and business ethics. She teaches on undergraduate and master level. She is author of chapters in books and articles in scientific and professional journals, published in Slovenia and abroad. 


\section{APPENDIX: Questionnaire}

Listed below are the questions from the questionnaire prepared for the topic of knowledge management in Serbia. Results are presented in chapter 4 . The questionnaire also included questions about companies, employee position and e-mail.

1. Does the company own a list of key skills required? Yes/No

2. How often do you conduct a comparison of required and available knowledge to identify the skills that are missing? (1) Once a month (2) Every three months (3) Every six months (4) Every year (5) As needed (6) Something else. What?

3. Provide (or provide your own estimate) the percentage of employees' education arising from:

(1) wishes and interests of employed (2) the current offer on the market (3) identified the real needs of enterprises

(4) others. What?

4. Indicate the number of employees who were further trained last year

5. Indicate the number of additional skilled of employed who left the organization last year

6. Indicate the number of employees, according to job classification, perform the tasks of knowledge management (relating to the activities of collecting, storing and transmitting information and knowledge)

7. Please indicate what percentage of new employees are (1) in order to fill the required number of employees (2) due to the specific knowledge and skills that are lacking in the organization (3) something else. What?

8. Does the company own its own library consisting of books and magazines in the field relevant to the organization? (1) it does. The library content is regulary supplemented by new literature. (2) it does, but the content is rarely replenished. (3) does not possess.

9. Is there an obligation of the enterprise for transferring interesting and acquired knowledge with conferences, workshops and the like? (1) there is. Employees should write a report which must be available to all employees or to maintain presentation. (2) there is. Employees should write a report that is not distributed to employees. (3) it does not exist, but employees usually informally transmit acquired skills. (4) does not exist.

10. The extent to which the company conducts practice meeting after completion of the projects, stating the knowledge and experience from the project? (1) always, after each project (2) it is carried out mostly (3) it is sometimes implemented (4) not implemented.

11. Which categories of employed have access to lessons learned from the projects and the best practices identified (it is possible to encircle more than one answer): (1) employees who participated in the project (2) managers responsible for the project (3) only some employees (4) all employees (5) others. Who?

12. What is the mission of your company?

13. Is there in your company the person who is responsible for enterprise-level knowledge management (ie, chief knowledge officer)? Yes/No

14. If your company has a person who is responsible for knowledge management, specify which hierarchical level is it located?

15. Please indicate in which department is the person responsible for knowledge management.

16. Give the job title of the person responsible for knowledge management. 
17. Is the employed contribution to knowledge management monitored in your company, in monitoring work performance? Yes/No

18. If it is monitored, state the percentage of employees who are followed.

19. How are employees rewarded for their contribution to knowledge management (it is possible to encircle more than one answer)? (1) by involvement in solving strategic issues (2) through the system, through the variable part of the salary or the predefined bonus (3) on the basis of a special decision on the contribution (4) a public recognition (5) a private praise (6) by joining the mentoring program (7) it is not rewarded (8) other. What?

20. Is there in a mentoring program in your company? (1) yes. Mentors are officially assigned to every or most of the new employees (2) yes. Mentors are officialy allocated to a small number of new employees (3) yes, but in an informal format (4) no.

21. Please indicate the percentage of employees participating in the mentoring program.

22. Check to what extent the conflicting statements describe your organization so that on scale of 1 to 7 , circle the number that best describes the principle of operations in your organization:

- a) open communication 1234567 communication solely through formal channels

- b) not a trusting 1234567 a trusting

- c) Innovative 1234567 closed to new ideas and solutions

- d) Individuals keep their knowledge on the basis of which generate a competitive advantage over colleagues 12345 67 employees readily share knowledge with colleagues

- e) employees openly say something when they do not know 1234567 employees hide their ignorance

- f) acquiring new knowledge depends solely on the initiative of enterprises 1234567 employees themselves are finding ways to acquire new knowledge

- g) in problem-solving, employees often consult their colleagues 1234567 employees usually solve their problems themselves

- h) employed often spend time in a conversation with colleagues 1234567 employed rarely take time for a conversation with fellow colleagues

23. Are there organized rooms designed for informal gatherings of employees during working hours? Yes/ No

24. Which information technology is used to support knowledge management in your company (type and name of the software).

In the following four questions highlight the extent to which your enterprise use the following IT functionality (via Intranet or other specific software you have one):

25. The communication platform that supports dynamic communication in the form of questions and answers, online surveys, and provides information about news within the company. (1) it is used to a great extent (2) is mainly used (3) it is sometimes used (4) not used.

26. platform for sharing knowledge that is used to manage documents (a system to support the management, archiving, changes, administration, search and deleting of documents). (1) it is used to a great extent (2) is mainly used (3) it is sometimes used (4) not used.

27. platform for sharing knowledge that serves as a knowledge base and allows easy archiving, categorizing and searching specific, expert knowledge. (1) it is used to a great extent (2) is mainly used (3) it is sometimes used (4) not used.

28. platform for sharing knowledge that serves as the yellow pages (ie. Yellow pages), or database that contains key knowledge and skills of employees. (1) it is used to a great extent (2) is mainly used (3) it is sometimes used (4) not used. 
29. If the company owns the yellow pages, the percentage of employees who are given data? (If there is no accurate data, enter your estimate!)

30. What percentage of employees for which data should be listed in the yellow pages? (If there is no accurate data, enter your estimate!)

31. How often are new documents or texts published by IT that enables document management? (1) everyday (2) every few days (3) once a week (4) every two weeks (5) once a month (6) miscellaneous. What?

32. Please indicate the percentage of employees that are enabled by IT association (email)?

33. Among the indicators developed for monitoring the performance of the entire enterprise, are there also those related to knowledge management? Yes/No

34. Are the experiences that confirm the importance and usefulness of knowledge management recorded and transferred in your company? Yes/No 